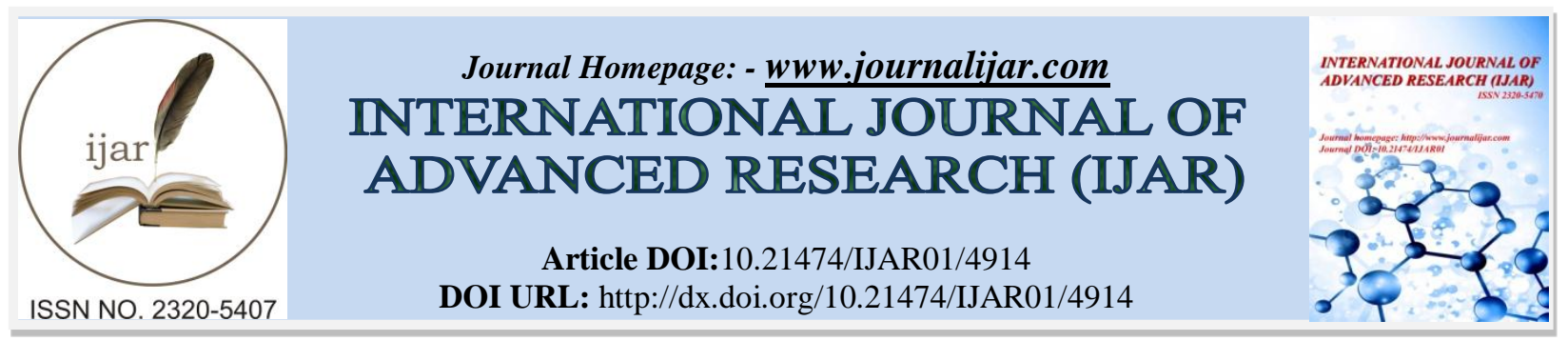

RESEARCH ARTICLE

\title{
PERCEPTION AND ATTITUDE OF STAFF NURSES ON USAGE OF ELECTRONIC HEALTH RECORD MONITORING.
}

\author{
Prof. Jayalakshmi ${ }^{1}$, Mrs. P. Vadivukkarasi Ramanadin ${ }^{2}$ and Ms. Anjali N Prajapati ${ }^{3}$. \\ 1. Principal, Shri Vinoba Bhave College of Nursing, Silvassa. \\ 2. Professor, Dept. of OBG (N), Shri Vinoba Bhave College of Nursing, Silvassa. \\ 3. Assistant Professor, Dept. of OBG (N), Shri Vinoba Bhave College of Nursing, Silvassa.
}

\section{Manuscript Info}

Manuscript History

Received: 22 May 2017

Final Accepted: 24 June 2017

Published: July 2017

Key words:-

Nursing informatics, PATCH (Pretest for attitudes toward computers in health (are) $)^{(1)}$ Inferential statistics \& Perception.

\section{Abstract}

Background: Technology is strongly influencing the today's world. Health care field also much persuaded by the evolving technology. Hence all the health care professionals should have up-to-date knowledge with current advancement. Knowledge develops when nurses combine $\&$ identify the relationship between different pieces of information.

Aim: The study was conducted to assess perception and attitude on Electronic Health Record Monitoring \& computer application in Health care among the staff nurses.

Methods: Quantitative approach with descriptive research design was used. Non- Probability convenient sampling technique was used to select 70 staff nurses working in Shri Vinoba Bhave Civil Hospital, Silvassa. Self administered semi structured questionnaire which consists of five sections. It includes socio-demographic variables, perception \& preference on EHRM \& Attitude by PATCH Scale. Results: Findings show that 27 of them had very low positive attitude, 12 of them had low positive attitude, 12 of them had very low negative attitude \& 19 of them had low negative attitude. According to PATCH Scale 3 of them had uneasiness to use computers in health care, 30 of them got limited awareness, 35 of them got realistic view $\&$ only 2 of them had enthusiastic view.

Conclusion: Present study shows that majority of the staff nurses are not having positive attitude towards EHRM. They are more comfortable with Case sheet method. This view can be changed by various method example in-service education programme on EHRM.

\section{Introduction:-}

Technology is changing the world hastily. Computer is one of the advent of technology. It plays vital role in our day today life. Computers are effective means of communication. Computers influence the entire field, health field is not exempted from that. Computers fascinated all the profession, it made most of our job very easier especially in health care profession. Computers stores most of the information related to the client. It is completely error free. Along with the current changes in the society nursing profession also need to mould, adhere \& adopt the recent advancement. According to ANA scope \& standards of nursing informatics practice, nursing informatics is a 
specialty that integrates nursing science, computer science \& information science to manage \& communicate data, information \& knowledge in nursing practice. ${ }^{(2)}$ Nursing informatics is very essential for nurses \& it is useful for integration of data, information \& knowledge to support client, nurses and other health care providers in their decision making in all roles \& settings. ${ }^{(3)}$ Various research findings denotes that nurses have less time for client care since they spent lot of time in documenting the client report by hand. This scenario is very common in developing \& under developed countries. Though nursing informatics is emerging branch of nursing, it doesn't even take up its buds in various countries. Changing the existing practice is one of the difficult tasks commonly. From the ancestor period many of our nurses were practicing documentation by hand written copy. Changing this practice will take much time. Hence this study is aimed to assess the attitude of staff nurses on Electronic Health record Monitor \& computer application in nursing care.

Our lives radically changed since the advent of computers. Computers are most reliable \& efficient tool for data processing. Back up of data is possible \& we can retrieve the data at any time. Though it has got its own flaw the data can be stored forever. ${ }^{(4)}$ Advance in technology is constantly evolving. In fast - paced world of nursing, nursing informatics plays an important role in helping nurses to make decision more rapidly \& accurately. As Nurses need to play a vital role in evaluating \& implementing new technological advances in their field. ${ }^{(2,3,4,5)}$ Computers minimize the wastage of resources \& provide more time for nursing care. The research report shows that there is an impact of EHR on nurses' time reported that using computers in hospitals was significantly associated with time saved for nurses that could be translated into financial savings. The time saved was attributed mainly to the flow of patient information between departments in the hospital. ${ }^{(4)}$ The other research also reported significant time savings that were attributed to nurses' use of a computerized system in the documentation processes in lieu of handwritten documentation. ${ }^{(6)}$ A randomized clinical trial reported reduction in nurses' documentation time that equated to an increase in direct patient care after installing a computerized system in the ICU. ${ }^{(7)}$ Hence this study is aimed to identify the attitude of staff nurses towards computer usage in health care setting \& Electronic health record monitoring.

\section{Materials and Methods:-}

Quantitative approach with descriptive research design was used. Non- Probability convenient sampling technique was used to select 70 staff nurses working in Shri Vinoba Bhave Civil Hospital, Silvassa. Self administered semi structured questionnaire was used to collect the data. The tool consists of five sections. Section- I includes Sociodemographic variables, Section- II includes Perception of staff nurses on Electronic Health record monitoring, Section -III includes Attitude of staff nurses on EHRM, Section - IV includes PATCH Scale a standardized tool with 50 items to assess an attitude towards computer application in health care setup. Study was analyzed by using both descriptive \& inferential statistics. Formal permission was obtained from Director cum Medical Superintendent, Shri Vinoba Bhave Civil Hospital, Silvassa. Oral consent were obtained from the Staff Nurses after explaining the study objectives \& ensuring the confidentiality.

\section{Results:-}

Table-1:- Frequency And Percentage Distribution Of Staff Nurses According To Their Socio- Demographic Variables

\begin{tabular}{|c|c|c|c|}
\hline \multirow{3}{*}{ Sl.No } & \multirow{3}{*}{ Socio- demographic variables } & & \\
\hline & & \multicolumn{2}{|c|}{ Total } \\
\hline & & Frequency (f) & Percentage (\%) \\
\hline \multirow[t]{5}{*}{1} & Age (in years) & 18 & 25.7 \\
\hline & $20-35$ & 35 & 50 \\
\hline & $26-30$ & 8 & 11.3 \\
\hline & $31-35$ & 9 & 13 \\
\hline & $\geq 36$ & 0 & 0 \\
\hline \multirow[t]{3}{*}{2} & Qualification & & \\
\hline & DGNM & 11 & 15.7 \\
\hline & B.Sc(N) & 59 & 84.3 \\
\hline \multirow[t]{4}{*}{3} & Designation & & \\
\hline & Staff nurse & 67 & 95.5 \\
\hline & Asst.Matron & 1 & 1.5 \\
\hline & Nursing Sister & 1 & 1.5 \\
\hline
\end{tabular}




\begin{tabular}{|c|c|c|c|}
\hline & Public Health Nurse & 1 & 1.5 \\
\hline \multirow[t]{5}{*}{4} & Year of Experience & & \\
\hline & $<1$ year & 9 & 12.8 \\
\hline & $2-5$ years & 29 & 41.4 \\
\hline & $6-10$ years & 23 & 33 \\
\hline & $\geq 11$ years & 9 & 12.8 \\
\hline \multirow[t]{11}{*}{5} & Ares of working & & \\
\hline & Medical Ward & 14 & 20 \\
\hline & Surgical Ward & 7 & 10 \\
\hline & Gynaec ward & 5 & 7 \\
\hline & Ortho & 4 & 5.7 \\
\hline & ICU & 17 & 24.3 \\
\hline & Casualty & 9 & 13 \\
\hline & Psychiatric Ward & 3 & 4 \\
\hline & Paediatric ward & 2 & 3 \\
\hline & NICU & 6 & 9 \\
\hline & Dialysis & 3 & 4 \\
\hline \multirow[t]{3}{*}{6} & Skill in Computer application & & \\
\hline & Yes & 59 & 84 \\
\hline & No & 11 & 16 \\
\hline \multirow[t]{6}{*}{7} & Source of Knowledge on Electronic Health Record & & \\
\hline & Friends \& Seniors & 30 & 43 \\
\hline & $\mathrm{CNE}$ & 29 & 42 \\
\hline & Mass media & 3 & 4 \\
\hline & Friends \& Mass media both & 3 & 4 \\
\hline & No & 5 & 7 \\
\hline
\end{tabular}

Table-2:- perception of staff nurses on electronic health record monitoring.

\begin{tabular}{|c|c|c|c|}
\hline \multirow{3}{*}{ Sl.No } & \multirow{3}{*}{ Perception on EHRM } & \multirow{2}{*}{\multicolumn{2}{|c|}{ Total }} \\
\hline & & & \\
\hline & & Frequency (f) & Percentage (\%) \\
\hline \multirow[t]{3}{*}{1} & Facility to monitor health data in computers & & \\
\hline & Yes & 66 & 94 \\
\hline & No & 4 & 6 \\
\hline \multirow[t]{4}{*}{2} & Necessity to use EHRM & & \\
\hline & Yes & 61 & 87 \\
\hline & No & 3 & 5 \\
\hline & No opinion & 6 & 8 \\
\hline \multirow[t]{10}{*}{3} & Use of EHRM for Nurses & & \\
\hline & Helps to know more about client & 1 & 2 \\
\hline & Les time consuming & 1 & 2 \\
\hline & Helps to recollect the data & 4 & 5 \\
\hline & Clear \& Accurate data & 1 & 2 \\
\hline & Easy \& useful & 1 & 2 \\
\hline & It strengthen the quality of nursing care & 1 & 2 \\
\hline & Permanent data & 1 & 2 \\
\hline & Helps to collect past history easily & 1 & 2 \\
\hline & No opinion & 59 & 81 \\
\hline \multirow[t]{3}{*}{4} & Is there any Drawback of using EHRM? & & \\
\hline & Yes & 39 & 56 \\
\hline & No & 31 & 44 \\
\hline \multirow[t]{3}{*}{5} & Drawback of using EHRM & & \\
\hline & Power off & 1 & 1 \\
\hline & Time consuming & 6 & 9 \\
\hline
\end{tabular}




\begin{tabular}{|l|l|l|l|}
\hline \multirow{4}{*}{} & Hanging & 1 & 1 \\
\cline { 2 - 4 } & No confidentiality & 2 & 3 \\
\cline { 2 - 4 } & Error & 1 & 1 \\
\cline { 2 - 4 } & Need more training & 2 & 3 \\
\cline { 2 - 4 } & No opinion & 57 & 82 \\
\hline \multirow{6}{*}{} & Preference to record & 32 & 46 \\
\cline { 2 - 4 } & Case sheet & 30 & 42 \\
\cline { 2 - 4 } & EHRM & 3 & 5 \\
\cline { 2 - 4 } & Both & 5 & 7 \\
\cline { 2 - 4 } & No opinion & & \\
\hline
\end{tabular}

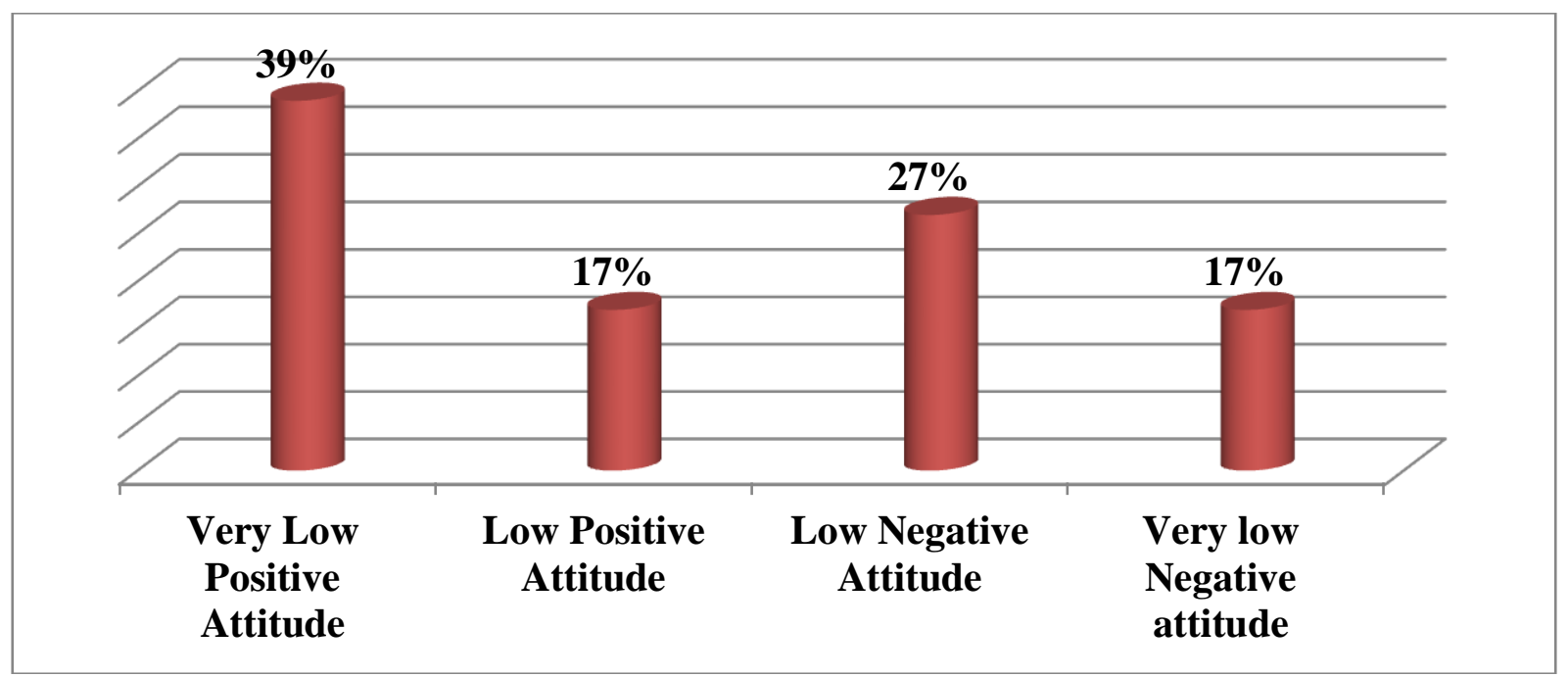

Figure-1:- Attitude Of Staff Nurses Towards Ehrm

Note:-Findings of the study show that 27 (39\%) of them had very low positive attitude, $12(17 \%)$ of them had low positive attitude, $12(17 \%)$ of them had very low negative attitude \& $19(27 \%)$ of them had low negative attitude.

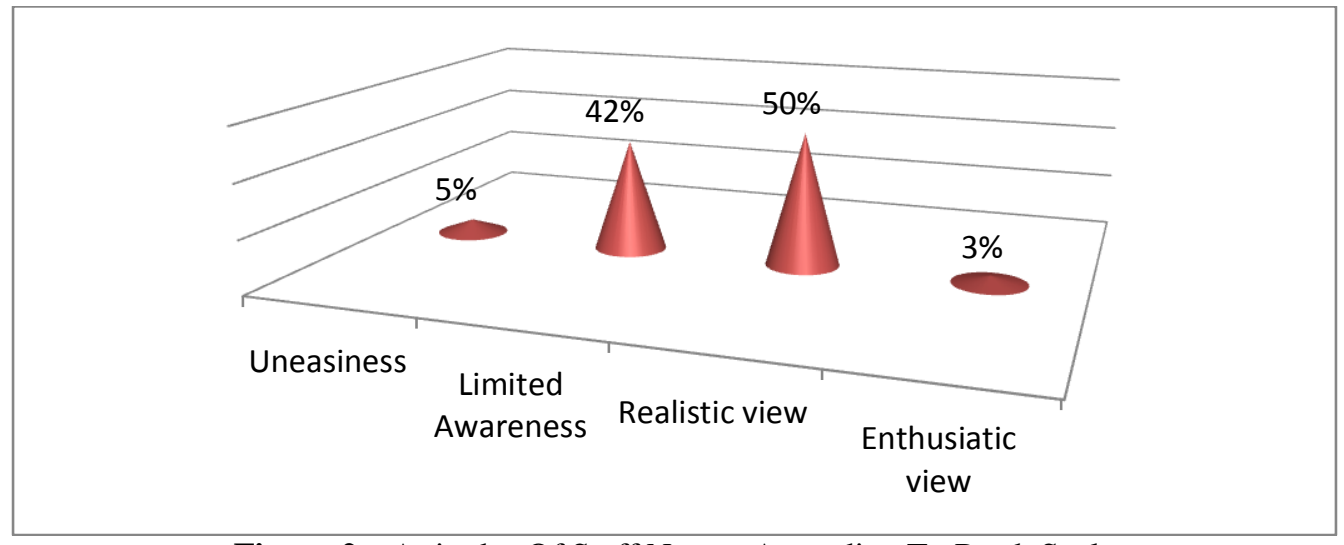

Figure 2:- Attitudes Of Staff Nurses According To Patch Scale

\section{Attitude of Staff Nurses according To PATCH Scale:-}

According to PATCH Scale $3(5 \%)$ of them had uneasiness to use computers in health care, $30(42 \%)$ of them got limited awareness, $35(50 \%)$ of them got realistic view \& only $2(3 \%)$ of them had enthusiastic view. 


\section{Discussion:-}

Finding denotes that maximum (84\%) number of Staff Nurses knew to operate computers \& $43 \%$ of them were aware of Electronic Health Record through Friends \& Seniors. It is supported by the study findings that the majority 75\% staff nurses had good computer knowledge, 50.8\% and 30.8\% had average and fair computer skills respectively (Raja), majority (75\%) of the staff nurses had good computer knowledge. (Punjab, ludhiyana), one third of the nursing staff had contact with computers prior to start of the study. ${ }^{(8)}$

Perception of Staff Nurses on Electronic Health Record Monitor shows maximum number of staff nurses (87) felt that there is a necessity to use EHRM. 81\% of them were expressed no opinion on uses of EHRM, $50 \%$ of them were mentioned that there is draw back in using EHRM out of which 9\% of them were expressed that time consuming is the common draw back. It also shows that $46 \%$ of them were preferred recording by hand written method \& $42 \%$ of them were preferred EHRM. In contrast to this findings the other study shows that $100 \%$ of nurses had positive attitudes towards computer utilization. ${ }^{(9)}$ The enthusiastic attitude of Staff nurses toward using computers on the ward was striking. Nursing staff expected that their work would be easier after the introduction of computers, that electronic data processing would save time, and that the computers would be easy to use. The staff did not express such positive expectations for the use of bedside terminals or portable devices. The results of the other study also shows that, on average, $15 \%$ of a nurse's time was spent providing general nursing care, $35 \%$ on special nursing care, and $30 \%$ on administrative activities. The remaining $20 \%$ was used for activities not directly related to nursing. ${ }^{(8)}$

Present study shows that $17 \%$ of the Staff Nurses have low positive attitude (17\%) towards computer application in nursing practice. Similar finding was observed in a study shows that Nurses had a favorable attitude towards computerization. Non-users had a significantly higher attitude score compared to the users $(p=0.0274){ }^{(10)}$ These finding were dissimilar with other findings conducted among the middle and functional level nurse managers. It reveals that nurse managers had very positive attitudes towards use of computers in provision of health care. ${ }^{(11)}$ $100 \%$ of nurses had positive attitudes towards computer utilization. 50.8\% and 30.8\% had average and fair computer skills respectively. No significant correlation was found between nurses computer knowledge, attitude and skills. ${ }^{(9)}$

Present study also shows according to PATCH Scale $3(5 \%)$ of them had uneasiness to use computers in health care, $30(42 \%)$ of them got limited awareness, $35(50 \%)$ of them got realistic view \& only 2 (3\%) of them had enthusiastic view. Similar findings were observed in a study which reveals that nurse managers had very positive attitudes towards use of computers in provision of health care. The attitudes of the nurse managers towards use of computers in nursing were not significantly influenced by accessibility to a computer, previous training in computer $(\mathrm{p}=0.05)$. However the length of practice as a nurse and the age of the respondents have negative influence on attitudes $(\mathrm{p}=0.05)$. Majority of the nurse managers $(85 \%, \mathrm{n}=91)$ did not have computer studies as part of their training in basic nursing, fifty one percent $(n=55)$ had received training in computers after their basic training in nursing. Majority of the nurses $98.1 \%(\mathrm{n}=105)$ desired to be trained in computer applications. Most nurse managers $(69.1 \%)$ on job training in computers. ${ }^{(11)}$

Computer technology has the potential to impact on the structure and delivery of healthcare, challenge the traditional roles and scope of practice, alter the existing boundaries and relationships and reinvent the clinical environment of nursing. ${ }^{(12)} \quad$ The results show that both nurses' informatics competencies and nursing computer system success do have influence on nursing organizational impact. ${ }^{(13)}$ The information systems in place in various hospitals differ in major ways; some have an impact on nursing resource use while others do not. Evidence is strong and consistent that computer systems that manage flow of information between nursing units and ancillary departments save time for nurses ${ }^{(6)}$

Hospitals with higher penetration of electronic health records had more RNs employed (coefficient $=0.234, \mathrm{P}=$ 0.002) compared with hospitals with low penetration of electronic health records, even when controlling for adjusted patient-day volumes. This difference decreased for hospitals with higher case-mix index values. ${ }^{(4)}$ There is also strong, but unreplicated, evidence that a work plan or electronic Kardex for each patient saves time at report. On the other hand, systems that emphasize on-line charting and not communications do not save time. ${ }^{(6)}$

\section{Implications:-}

Nursing informatics is very useful for integration of data, information \& knowledge to support patients, nurses \& other providers in their decision making in all roles \& settings. Findings of the study reveals that staff nurses are 
having less awareness, uneasiness \& negative attitude towards computer application in health care setting. This study insists on developing organizational policies and procedures to implement electronic documentation. It also specifies that to create awareness \& educate the staff nurses on the benefit of using computers \& electronic documentation. The present study also recommends the nursing curriculum should include nursing informatics $\&$ train the students to apply the technology in day to day nursing care activities. This study suggests a Post graduation programme in nursing informatics to strengthen the nursing profession for improving Quality of care.

\section{Conclusion:-}

Nurses need to play a role in evaluating \& implementing new technological advances. Focus of nursing care is not the machine or technology it is client. Present study shows that majority of the staff nurses are not having positive attitude towards Electronic Health Record Monitoring \& not having enthusiastic \& idealistic view towards using computers in health care. There are more comfortable with Case sheet method. This view can be changed by various method example in-service education programme on EHRM. The value of nursing informatics is highly emphasized nowadays. Therefore nurse administrators and nurse educators must create and play a important role in helping hospitals to apply information technology slowly into the nursing activities by the employed nurses.

\section{Reference:-}

1. P.A.T.C.H. Assessment Scale v. 3 (Pretest for Attitudes Toward Computers in Healthcare) (C) June Kaminski 1996 2012. Retrieved from http://nursing-informatics.com/niassess/plan.html

2. Berman A, Snyder S J. Contemporary health Care, In: Kelly Trakalo, editor. Kozier \& Erb's Fundamentals of Nursing. Concepts, Process \& Practice. $9^{\text {th }}$ ed. New Jersey: Pearson; 2012. P.144-157.

3. Potter P A, Perry AG, Stockert PA, Hall AM. Professional Standards in Nursing Practice, Documentation \& Informatics. In: Fundamentals of Nursing. $8^{\text {th }}$ ed. Missouri: Elsevier Mosby; 2013. P.359-62.

4. Abbass I, Helton J, Mhatre S, Sansgiry SS. Impact of electronic health records on nurses' productivity. Comput Inform Nurs [Pub Med]. 2012 May;30(5):[237-41]. Available from: http://www.ncbi.nlm.nih.gov/pubmed/22411416

5. Taylor CR, Lillis C, Lemone P, Lynn P. Fundamentals of nUrsing, The art and Science of Nursing care. $7^{\text {th }}$ ed. Philadelphia: Wolters Kluwer Health / Lippincott Williams \& Wilkins; 2011. p. 351-52.

6. Hendrickson G, Kovner CT. Effects of computers on nursing resource use. Do computers save nurses time?. Comput Nurs [PubMed]. 1990 Jan-Feb;8(1):[16-22]. Available from: http://www.ncbi.nlm.nih.gov/pubmed/2405962

7. Bosman RJ, Rood E, Oudemans-van SHM, Van der SJI, Wester JP, Zandstra DF. Intensive care information system reduces documentation time of the nurses after cardiothoracic surgery. Intensive Care Med [Pub Med]. 2003 Jan; 29(1):[83-90]. Epub 2002 Nov 22. Available from: http://www.ncbi.nlm.nih.gov/pubmed/12528027

8. Burkle T, Kuch R, Passian A, Prokosch U, Dudeck J. The impact of computer implementation on nursing work patterns: study design and preliminary results. Medinfo [PubMed]. 1995;8 Pt 2: [1321-5]. Available from: http://www.ncbi.nlm.nih.gov/pubmed/8591437

9. Raja EEJ, Mahal R, Masih VB. An Exploratory Study to Assess the Computer Knowledge, Attitude and Skill Among Nurses in Health care Setting of a Selected Hospital, Ludhiana, Punjab, India. Online Journal of Nursing Informatics (OJNI). 2004 February; 8(1). Available from: http://ojni.org/8_1/raja.htm

10. Mathew KK, Lucy WKB, Ann KK, Margaret MM. Attitudes of nursing staff towards computerisation: a case of two hospitals in Nairobi, Kenya. BMC Medical Informatics and Decision Making. 2014 December. Available from: http://link.springer.com/article/10.1186\%2F1472-6947-14-35\#/page-1

11. Kipturgo MK, Kivuti-Bitok LW, Karani AK, Muiva MM. Attitudes of nursing staff towards computerisation: a case of two hospitals in Nairobi, Kenya. BMC Med Inform Decis Mak. 2014 Apr 29;[14:35]. Available from: http://www.ncbi.nlm.nih.gov/pubmed/24774008

12. Alexander PJ. The Impact of Computer Technology in the Clinical Setting: A Nursing perspective. University of Southern Queensland. 2007 - [cited 2013Jul 2]. Available from: http://eprints.usq.edu.au/4282/

13. Lin $\mathrm{HC}$, Hsu MH, Yang $\mathrm{CW}$. The influences of computer system success and informatics competencies on organizational impact in nursing environments. Comput Inform Nurs [PubMed]. 2014 Feb;32(2);[90-9]. Available from: http://www.ncbi.nlm.nih.gov/pubmed/24132084 